\title{
DC-DC 3SSC-A-Based Boost Converter: Analysis, Design, and Experimental Validation
}

\author{
Lucas Carvalho Souza ${ }^{1,2, *}$, Douglas Carvalho Morais ${ }^{1}$, Luciano de Souza da Costa e Silva ${ }^{2}$, \\ Falcondes José Mendes de Seixas ${ }^{1}$ (D) and Luis De Oro Arenas ${ }^{3}$ * (D) \\ 1 Power Electronics Laboratory—LEP, Electrical Engineering Department, São Paulo State University—UNESP, \\ Ilha Solteira 15385-000, SP, Brazil; morais.sccp.carvalho@gmail.com (D.C.M.); \\ falcondes.seixas@unesp.br (F.J.M.d.S.) \\ 2 Goias Federal Institute of Education, Science, and Technology, Jataí 75804-714, GO, Brazil; \\ luciano.souza@ifg.edu.br \\ 3 Group of Automation and Integrated Systems, São Paulo State University—UNESP, \\ Sorocaba 18087-180, SP, Brazil \\ * Correspondence: lucas.souza@ifg.edu.br (L.C.S.); luis.arenas@unesp.br (L.D.O.A.)
}

Citation: Souza, L.C.; Morais, D.C.; Silva, L.d.S.d.C.e.; Seixas, F.J.M.d.; Arenas, L.D.O. DC-DC 3SSC-A-Based Boost Converter: Analysis, Design, and Experimental Validation. Energies 2021, 14, 6771. https://doi.org/ $10.3390 /$ en14206771

Academic Editors: Valeria Boscaino and Vincenzo Di Dio

Received: 17 September 2021

Accepted: 5 October 2021

Published: 17 October 2021

Publisher's Note: MDPI stays neutral with regard to jurisdictional claims in published maps and institutional affiliations.

Copyright: (C) 2021 by the authors. Licensee MDPI, Basel, Switzerland. This article is an open access article distributed under the terms and conditions of the Creative Commons Attribution (CC BY) license (https:// creativecommons.org/licenses/by/ $4.0 /)$.

\begin{abstract}
A detailed analysis and validation of the DC-DC boost converter based on the three-state switching cell (3SSC) type-A are presented in this paper. The study of this topology is justified by the small amount of research that employs 3SSC-A and the advantages inherent to 3SSC-based converters, such as the division of current stresses between the semiconductors, the distribution of thermal losses, and the high-density power. Therefore, a complete static analysis of the converter is described, as well as the study of all voltage and current stresses in the semiconductors, the development of a loss model in all components, and a comparison with other step-up structures. Additionally, the small-signal model validation is accomplished by comparing the theoretical frequency response and the simulated AC sweep analysis. Finally, implementing a simple controller structure, the converter is experimentally validated through a $600 \mathrm{~W}$ prototype, where its overall efficiency is examined for various load conditions, reaching $96.8 \%$ at nominal load.
\end{abstract}

Keywords: boost converter; DC-DC converter; right-half-plane (RHP) zero; three-state switching cell (3SSC); 3SSC type-A

\section{Introduction}

DC-DC converters play a key role in energy conversion and conditioning applications that require reduced weight and size, such as electric and hybrid vehicles, aeronautical equipment, space probes and satellites, renewable energy systems, among other applications [1-3]. With regard to the development of topologies for DC-DC converters, there is a trend in the search for equipment with a higher power density, and advances are mainly motivated by the requirements of lower cost and volume [4]. In this scenario, researchers have been focused on finding ways to improve and overcome the limitations in the power processing capacity of classic DC-DC converters. Among the various approaches, the soft switching techniques can be mentioned, which lead to greater efficiency in energy conversion, but the cost and complexity increase due to the multiple elements of the resonant tank network [5].

The interleaving technique in power electronics converters is the usual solution to achieve high power levels and modularity, however, the appropriate current sharing between the association of multiple cells should be taken into consideration, which demands the use of sophisticated control schemes to maintain the current balance between the semiconductors [6]. Similar to interleaving solutions, the three-state switching cell (3SSC) was introduced in [7], being an interesting solution for increasing power density, with a high efficiency level, and without the need for special control strategies.

Since the 3SSC was proposed, a variety of topologies for DC-DC, AC-DC, and DC-AC converters have been presented in the literature [8-10]. All of these approaches present 
interesting advantages inherent to the application of the 3SSC, i.e., reduction of weight and volume of the filter elements, current stress division between the semiconductors and, consequently, distribution of the losses, providing the reduction of the heat-sink's size [11-13]. Although the 3SSC uses a high-frequency autotransformer, its dimensions are compact, because that element operates at twice the switching frequency and only in two quadrants of the B-H curve [14].

It is noteworthy that most of the applications with 3SSC mainly use the type-B cell (3SSC-B) topology [15]. It could be associated with the fact that the 3SSC-B-based buck, boost and buck-boost converters have a static gain identical to the classic non-isolated converters, in the whole range of duty cycle, when they operate in continuous conduction mode (CCM). This characteristic has been an attractive solution for the development and exploration of new non-insulated step-up DC-DC structures by employing the 3SSC-B [16-19].

Nevertheless, a characteristic of classic boost converters, including the 3SSC-B-based boost, is the right-half-plane (RHP) zero in the control-to-output-voltage transfer function in CCM. This fact causes the non-minimum phase characteristic, imposing limitations for the bandwidth and the dynamic response in the control-loop by using single-loop control architectures, i.e., to ensure stability with adequate damping [20]. These limitations have motivated the effort to develop step-up structures that have a satisfactory dynamic performance without the need to apply cascade or complex control architectures [21-23].

In this context, the DC-DC 3SSC-A-based boost topology, initially proposed by [7] and briefly explored by the authors in [24], becomes an interesting alternative in step-up converters with minimum phase characteristic, where a faster dynamic response can be attended by employing a simple closed-loop control scheme with a single-loop control, which also reduces computational and signal conditioning costs in practical implementations.

Therefore, taking into account the reduced amount of research that employs the 3SSC-A and the advantages presented by 3SSC-based converters, this paper fills a gap in the literature with the following contributions:

- A generalized and detailed static analysis of the DC-DC 3SSC-A-based boost converter, including highlighting the discontinuous conduction mode (DCM) and critical conduction mode (CRM).

- A complete theoretical study of voltage and current stresses in semiconductors, comparison with other step-up structures with minimum phase characteristics, description of a loss model in all components, as well as the validation of the small-signal model by simulation results.

- Verification of the dynamic response of the control scheme with a single-loop architecture and the efficiency under several load conditions by experimental results.

This paper is organized as follows, Section 2 describes the converter analysis, including loss models, modeling and design considerations. A comparison with similar converters is detailed in Section 3. Section 4 presents the experimental validations, followed by the final considerations.

\section{The 3SSC-A-Based Boost: Static Analysis}

The 3SSC-A-based boost converter consists of an autotransformer with windings $\left(T_{1}, T_{2}\right)$, two controlled switches $\left(S_{1}, S_{2}\right)$, two diodes $\left(D_{1}, D_{2}\right)$, one inductor $(L)$, and an equivalent load $\left(R_{o}\right)$ connected in parallel with the output capacitor $\left(C_{o}\right)$, as shown in Figure 1 . This topology must operate with a duty cycle less than 0.5 , in order to avoid the switches working on overlapping condition, which could be considered as a disadvantage of the 3SSC-A-based converters. In this section, the operation principle in steady state is analyzed. 

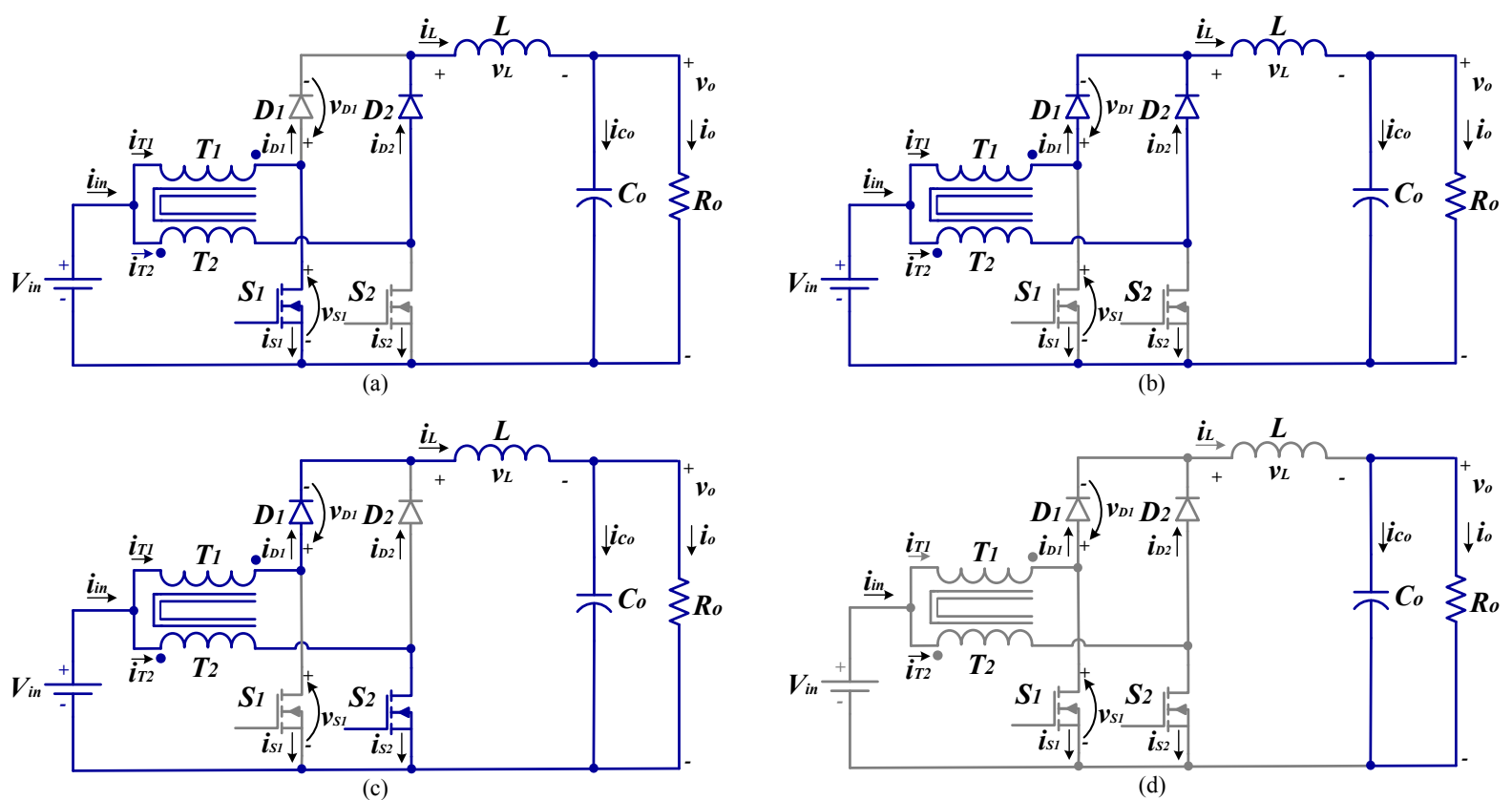

Figure 1. Equivalent circuits of the operation stages of 3SSC-A-based boost: (a) First mode. (b) Second mode. (c) Third mode. (d) Fourth mode.

\subsection{Operation Principle}

The operation principle study of the 3SSC-A-based boost converter is accomplished under CCM, DCM, and CRM, by considering all of converter's components as ideal elements, with electrical variables defined as follows:

$V_{G S_{1,2}}$ - command signals of switches $S_{1}$ and $S_{2} ;$

$i_{\text {in }}(t)$-input current;

$i_{S_{1}}(t)-S_{1}$ switch current;

$i_{D_{1}}(t)-D_{1}$ diode current;

$i_{L}(t)$-inductor current,

$i_{o}(t)$-load current;

$i_{C_{0}}(t)$-capacitor current;

$v_{S_{1}}(t)-S_{1}$ switch voltage;

$v_{D_{1}}(t)-D_{1}$ diode voltage;

$v_{L}(t)$-inductor voltage.

\subsubsection{CCM}

The equivalent circuits in CCM and the main theoretical waveforms, defined according to four operation modes, are shown in Figures $1 \mathrm{a}-\mathrm{c}$ and $2 \mathrm{a}$, respectively.

First Stage $\left(t_{0}<t<t_{1}\right)$ (Figure 1a)

Initially, the switch $S_{1}$ is turned on, while the switch $S_{2}$ is turned off. The autotransformer's windings' currents are equivalent to half of the input current $i_{i n}$, which is guaranteed by the unitary turns ratio and, consequently, the voltages on the windings $T_{1}$ and $T_{2}$ are equal to $V_{i n}$. Thus, the current $i_{T_{1}}$ flows through the switch $S_{1}$, the current $i_{T_{2}}$ flows through the diode $D_{2}$ and the inductor $L$ stores energy. Considering that the autotransformer's windings have the same impedance, the voltages on $T_{1}$ and $T_{2}$ are equal and equivalent to $V_{i n}$. 


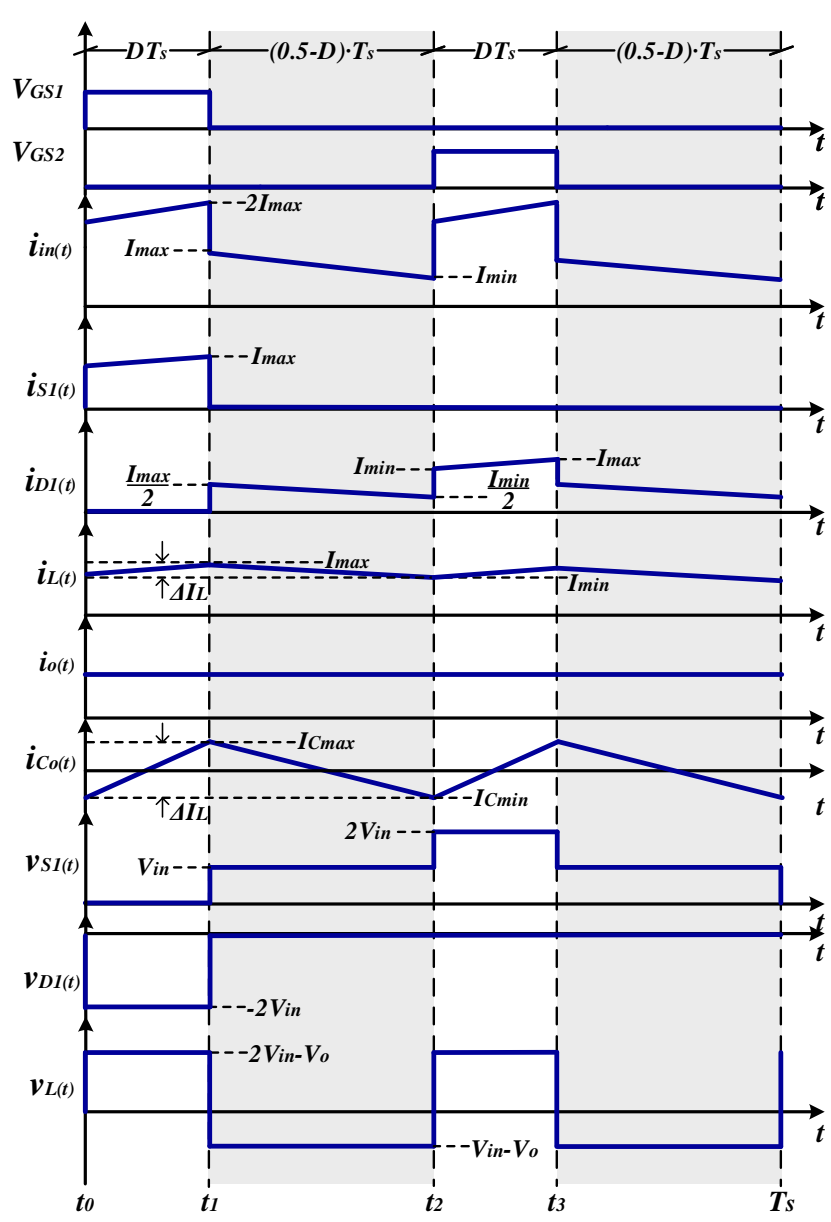

(a)

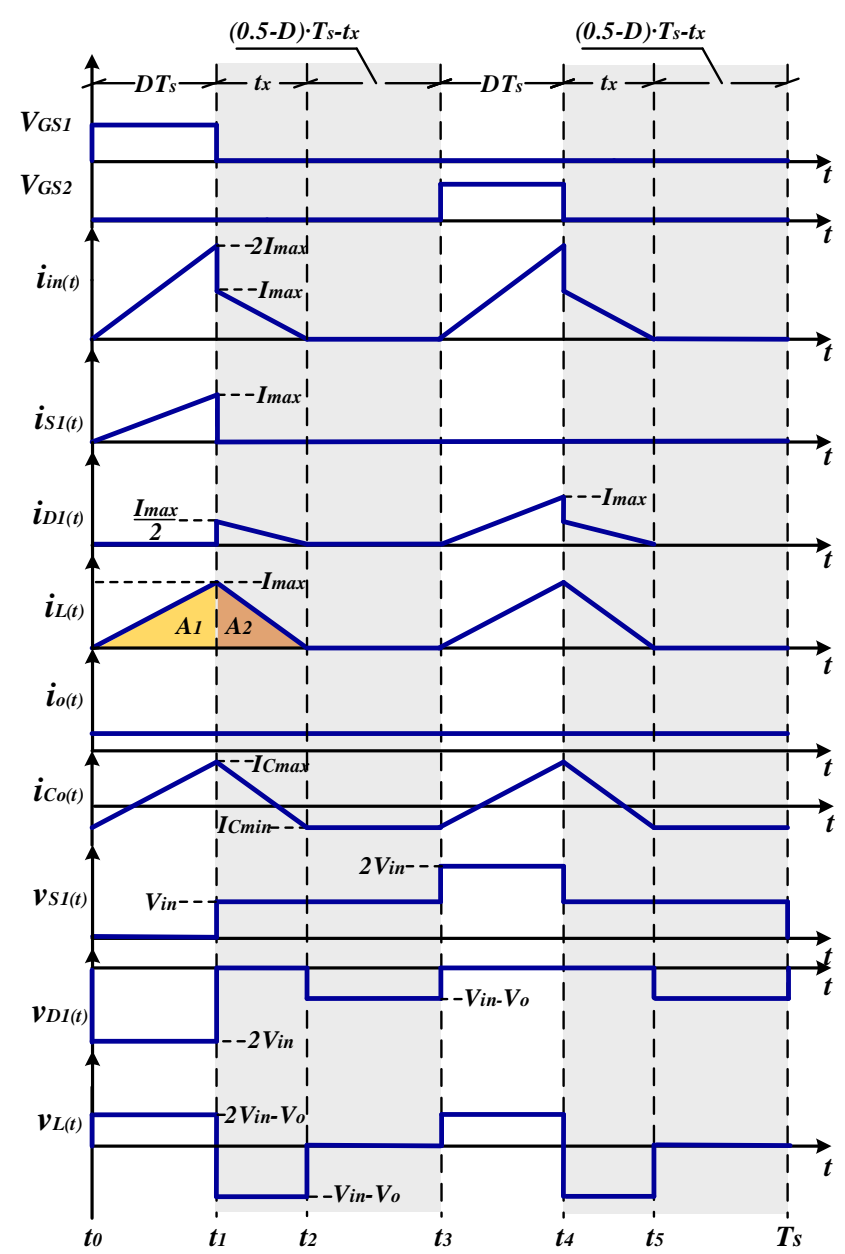

(b)

Figure 2. Main theoretical waveforms: (a) CCM. (b) DCM.

Second Stage $\left(t_{1}<t<t_{2}\right)$ (Figure $1 \mathrm{~b}$ )

The switch $S_{1}$ is turned off and the diode $D_{1}$ is turned on. While $S_{2}$ and $D_{2}$ remain turned off and turned on, respectively. The current flowing through $T_{1}$ and $T_{2}$ and the magnetic flux in the autotransformer core is null. Thus, the polarity of $V_{L}$ is inverted and the stored energy in the inductor $L$ is transferred to the load.

Third Stage $\left(t_{2}<t<t_{3}\right)$ (Figure 1c)

This stage is similar to the operation stage 1 , where, the switch $S_{2}$ is turned on and $S_{1}$ remains turned off. The diode $D_{1}$ continues turned on and $D_{2}$ is turned off.

Fourth Stage $\left(t_{3}<t<T_{s}\right)$ (Figure $\left.1 b\right)$

This stage is identical to the second stage, where the inductor current flows through the diodes $D_{1}, D_{2}$ and the autotransformer windings.

\subsubsection{DCM}

This operation mode present six equivalent operation stages defined according to the theoretical waveforms shown in Figure 2b. Some of the operation stages in DCM are equivalent to the CCM and these will not be described in detail.

First Stage $\left(t_{0}<t<t_{1}\right)$ (Figure 1a)

This stage is identical to the first stage in CCM. 
Second Stage $\left(t_{1}<t<t_{2}\right)$ (Figure 1b)

This stage is identical to the second stage when the converter is operating in CCM.

Third Stage $\left(t_{2}<t<t_{3}\right)$ (Figure 1d)

In this stage, the current in the inductor becomes zero, the switches $S_{1}$ and $S_{2}$ remain turned off, and diodes $D_{1}$ and $D_{2}$ are turned off. Thus, there is not power transfer from the input source to the load. The power supplied to the load comes from the $C_{o}$ output capacitor.

Fourth Stage $\left(t_{3}<t<t_{4}\right)$ (Figure 1c)

Identical to the third stage of the CCM.

Fifth Stage $\left(t_{4}<t<t_{5}\right)$ (Figure $1 \mathrm{~b}$ )

Identical to the fourth stage of the CCM.

Sixth Stage $\left(t_{5}<t<T_{s}\right)$

Identical to the third stage of the DCM.

In Figure $2 b$, it is verified that the current in the inductor is null during the third and sixth operation stages, characterizing the DCM. Semiconductors are subjected to a maximum voltage equivalent to twice the input voltage $V_{i n}$.

\subsubsection{CRM}

In this mode, maintaining the 180-degree delay, each switch is turned on at the exact moment when the current in the inductor becomes null, causing the current to increase again. The inductor current becomes null every half-time, so the minimum current $I_{m}$ is equal to zero and the current ripple $\Delta I_{L}$ in the inductor is equal to its maximum current $I_{M}$. The first and second operation stages in CRM are equivalent to the first and second stages in DCM, respectively.

\subsubsection{Output Characteristic of the Converter}

The static gain for each operation mode: CCM, DCM, and CRM are expressed as (1), (2), and (3) respectively.

$$
\begin{gathered}
G_{C C M}=1+2 D \\
G_{D C M}=\frac{2 D^{2}+\gamma}{D^{2}+\gamma} \\
G_{C R M}=1+\left[\frac{1}{2} \pm 2 \sqrt{\frac{1}{16}-\gamma}\right]
\end{gathered}
$$

where, $I_{0}$ is the average output current, $f_{s}$ is the switching frequency, $D$ is the duty cycle, and $\gamma$ represents the normalized output current, defined in (4).

$$
\gamma=\frac{L I_{o} f_{s}}{V_{i n}}
$$

From (1)-(3), the static gain curves of the proposed converter are presented in Figure 3. Analogously to the classic boost converter, the output voltage is a function of the load current in DCM. The maximum static gain in CRM occurs at $\gamma=0.0625$ and $D=0.25$ for the 3SSC-A-based boost converter, which differs from the classic boost converter, whose maximum gain in CRM occurs at $\gamma=0.125$ and $D=0.5$. In this regard, the CCM region is wider for the 3SSC-A-based boost converter, i.e., for the same operating point, the inductance becomes half of that required for the classical boost converter. 


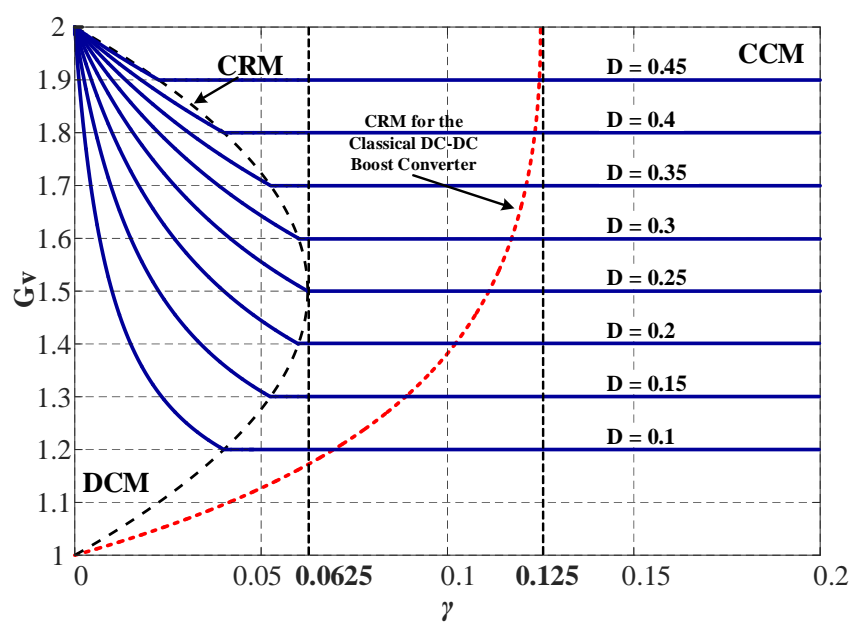

Figure 3. Comparison between static gain curves of the conventional and 3SSC-A-based boost converters.

\subsubsection{Filter Elements}

The inductor current ripple $\Delta I_{L}$, described in (5), can be obtained applying Kirchhoff's voltage law to Figure 1a.

$$
\Delta I_{L}=\frac{(1-2 D) D V_{o}}{(1+2 D) L f_{s}}
$$

The normalized current ripple $\overline{\Delta I_{L}}$ is given by (6) and plotted in Figure 4, where it can be seen that the maximum value occurs at $D=0.2072$.

$$
\overline{\Delta I_{L}}=\frac{L f_{s} \Delta I_{L}}{V_{o}}=\frac{(1-2 D) D}{(1+2 D)}
$$

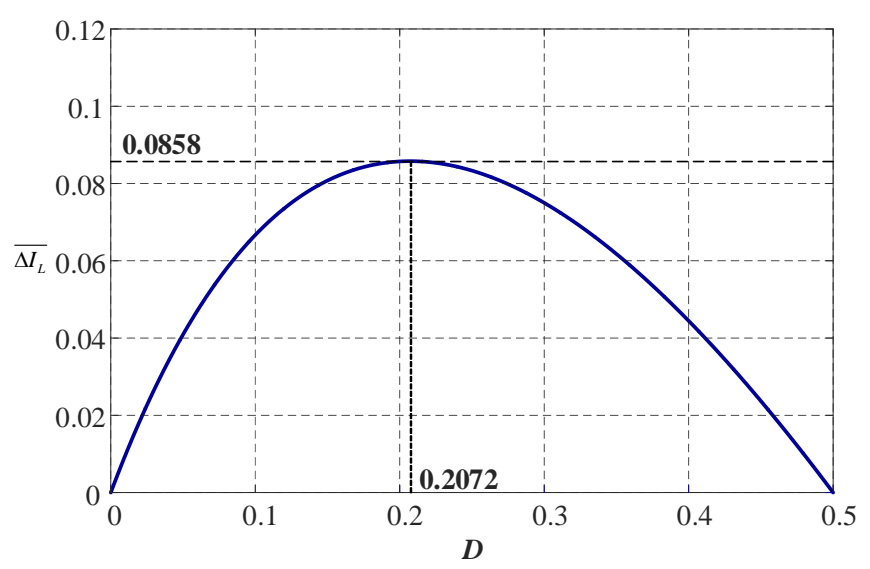

Figure 4. Ripple current through the inductor.

The inductance $L$ is determined by reorganizing (5), according to (7).

$$
L=\frac{(1-2 D) D V_{o}}{(1+2 D) \Delta I_{L} f_{\mathcal{S}}}
$$

The critical inductance $L_{c r i t}$, described in (8), corresponds to the threshold value of inductance between CCM and DCM. From Figure 3, the threshold value of $\gamma$ is 0.0625 , and the critical inductance is calculated by replacing that value in (4).

$$
L_{c r i t}=\frac{V_{\text {in }}}{\gamma_{\text {thr }} I_{0} f_{s}}=\frac{V_{\text {in }}}{16 I_{o} f_{s}}
$$


Considering the charge variation on the capacitor $C_{0}$ during a switching period, the minimum capacitance required to obtain the desired voltage ripple $\Delta V_{o}$ is given by (9).

$$
C_{o} \geqslant \frac{1}{16} \frac{(1-2 D) D V_{i n}}{L f_{s}^{2} \Delta V_{o}}
$$

\subsection{Semiconductors Stresses in CCM}

The average and RMS values of the switches currents are given by (10) and (11), respectively.

$$
\begin{gathered}
I_{S_{A V G}}=D I_{O} \\
I_{S_{R M S}}=\sqrt{D\left(I_{o}^{2}+\frac{\Delta I_{L}^{2}}{12}\right)}
\end{gathered}
$$

The average and RMS values of the diodes currents are given by (12) and (13), respectively.

$$
\begin{gathered}
I_{D_{A V G}}=\frac{I_{O}}{2} \\
I_{D_{R M S}}=\sqrt{\frac{1}{12}(1+2 D)\left(3 I_{o}^{2}+\frac{\Delta I_{L}^{2}}{4}\right)}
\end{gathered}
$$

The maximum voltage stress across the switches and diodes is given by (14) and (15), respectively.

$$
\begin{gathered}
V_{S(\max )}=2 V_{i n} \\
V_{D(\max )}=-2 V_{i n}
\end{gathered}
$$

Semiconductor losses are described according to $[25,26]$. Hence, the conduction and switching losses of the IGBT are given by (16) and (17), respectively.

$$
\begin{gathered}
P_{\left.S_{(} \text {cond }\right)}=V_{C E_{(s a t)}} I_{S_{A V G}} \\
P_{S_{(s w)}}=\frac{f_{s}}{2} V_{i n} I_{S_{\text {peak }}}\left(t_{o n}+t_{o f f}\right)
\end{gathered}
$$

where $I_{S_{\text {peak }}}$ is the peak of the current switch, $V_{C E(s a t)}$ is the collector-emitter saturation voltage, and $t_{o n}$ and $t_{\text {off }}$ are the turn-on and turn-off switching times. For the diodes, only the conduction losses and the reverse recovery losses, occurring at the switch off, can be considered, described by (18) and (19), respectively.

$$
\begin{gathered}
P_{D_{(\text {cond })}}=V_{F} I_{D_{A V G}}+R_{D} I_{D_{R M S}}^{2} \\
P_{D_{(s w)}}=\frac{f_{s}}{2} t_{r r} I_{r} V_{D(\max )}
\end{gathered}
$$

where $V_{F}$ is the forward voltage, $R_{D}$ is the dynamic resistance, $t_{r r}$ is the reverse recovery time, and the $I_{r}$ is the maximum instantaneous reverse current.

\subsection{Autotransformer Design and Losses}

The selection of the high-frequency transformer can be defined by the product of the core magnetic cross-section area $A_{e}$ and the window area $A_{w}$ [27]. This relationship, 
known as the core area product $A_{e} A_{w}$, is defined in (20) as a function of the converter's electromagnetic parameters.

$$
A_{e} A_{w}=\frac{P_{o}}{4 f_{s} B_{\max } J_{\max } \eta}
$$

where $P_{o}$ is the output power, $B_{\max }$ is the maximum flux density, $J_{\max }$ is the maximum current density, and $\eta$ is the window utilization factor.

Since the turn ratio of the autotransformer is unitary, the number of turns in each winding is found from (21).

$$
N_{T}=\frac{V_{\text {in }} D_{\max }}{2 B_{\max } A_{e} f_{s}}
$$

where $D_{\max }$ is the maximum duty cycle.

The average and RMS current through the autotransformer windings $T_{1}$ and $T_{2}$ is given by (22) and (23), respectively.

$$
\begin{gathered}
I_{T_{A V G}}=\frac{(1+2 D) I_{o}}{2} \\
I_{T_{R M S}}=\sqrt{\frac{1}{12}(1+6 D)\left(3 I_{O}^{2}+\frac{\Delta I_{L}^{2}}{4}\right)}
\end{gathered}
$$

The estimation of autotransformer losses is based on the methodology presented in $[28,29]$. Thus, the total losses $P_{T}$ are equal to the core losses $P_{\text {Tcore }}$ plus the copper losses $P_{\text {Tcopper }}$, defined by (24).

$$
P_{T}=P_{\text {Tcore }}+P_{\text {Tcopper }}
$$

The total core losses vary essentially as a function of the AC magnetic flux density and the operating frequency, whose relationship can be represented by the improved Steinmetz Equation (25).

$$
P_{\text {Tcore }}=4^{\alpha} k f_{s}^{\alpha} B_{p k}^{\beta} V_{\text {core }}
$$

where $k, \alpha$, and $\beta$ are extracted from the core loss per volume unit based on the value of flux density and frequency, from the datasheet provided by the manufacturer. $V_{\text {core }}$ is the core volume and $B_{p k}$ is defined as half of the peak AC flux density.

It is noteworthy that the $f_{s} B_{p k}$ merit figure is directly related to the total losses in the core and is inversely proportional to the core magnetic volume. Thus, in practical design, it is up to the designer to adjust the losses and volume parameters.

The total copper losses include the sum of losses in the $T_{1}$ and $T_{2}$ windings, given by (26).

$$
P_{\text {Tcopper }}=\frac{2 \rho_{c u} l_{w d g} I_{T_{R M S}}^{2}}{n A_{c u}}
$$

where $\rho_{c u}$ is the copper resistivity constant, $l_{w d g}$ denotes the length of winding, $n$ is the number of litz wires, and the core cross-sectional are $A_{c u}$.

\subsection{Inductor Losses}

The average and RMS current through the inductor is given by (27) and (28), respectively.

$$
I_{L_{A V G}}=I_{o}
$$




$$
I_{L_{R M S}}=\sqrt{I_{o}^{2}+\frac{\Delta I_{L}^{2}}{12}}
$$

The calculation of losses in the inductor is similar to that of an autotransformer, i.e., the total losses are split into the copper losses and core losses

$$
P_{L}=P_{\text {Lcore }}+P_{\text {Lcopper }}
$$

The copper loss is defined by (30).

$$
P_{\text {Lcopper }}=\frac{\rho_{c u} l_{w d g} I_{L_{R M S}}^{2}}{n A_{c u}}
$$

The core losses in the inductor can be obtained applying Equation (25), taking into account that for a small AC component of current, $L$ can be assumed constant throughout AC excitation, then $B_{p k}$ is given by

$$
B_{p k}=\frac{L \Delta I_{L}}{2 N_{L} A_{e}}
$$

where $N_{L}$ is the number of turns of the inductor.

\subsection{Capacitor Losses}

The RMS current through the capacitor are given by

$$
I_{C_{R M S}}=\sqrt{\frac{\Delta I_{L}^{2}}{12}}
$$

Power dissipation on the capacitor can be expressed as function of the RMS current $I_{C_{R M S}}$ through the equivalent series resistance ESR:

$$
P_{C}=I_{C_{R M S}}^{2} E S R
$$

\subsection{Transfer Function and Control Design}

The adopted modeling technique is based on the basic AC modeling approach proposed in [30]. In this regard, aiming to obtain the small-signal AC equivalent circuit, as shown in Figure 5, small-signal perturbations are applied around the equilibrium point, and its frequency response is validated by the AC sweep analysis performed in PSIM ${ }^{\circledR}$ software (UNESP, Ilha Solteira, Brazil), as shown in Figure 6a. From that circuit, the control-to-output $G_{v d}(s)$ and line-to-output $G_{v g}(s)$ transfer functions are obtained and are described by (34) and (35), respectively.

$$
\begin{aligned}
& G_{v d}(s)=\frac{2 V_{i n}}{s^{2} L C_{o}+s \frac{L}{R_{o}}+1} \\
& G_{v g}(s)=\frac{1+2 D}{s^{2} L C_{o}+s \frac{L}{R_{o}}+1}
\end{aligned}
$$




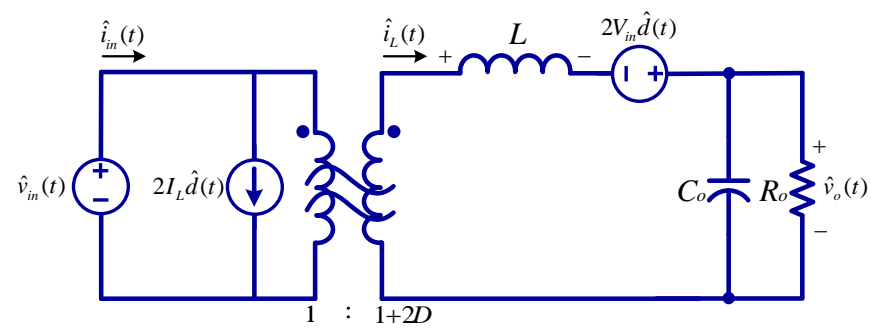

Figure 5. Small-signal AC equivalent circuit of the 3SSC-A-based boost.

By analyzing the transfer function $G_{v d}$, the proposed converter behaves as a minimum-phase system, due to the absence of right-half-plane (RHP) zeros. Therefore, the controller design process is simplified for the 3SSC-A-based boost converter and the problems associated with right-half-plane (RHP) zeros are eliminated. Thus, it is possible to obtain a satisfactory dynamic response without implementing an additional control loop. Moreover, it is observed that the dynamic characteristics are similar to the classic buck converter operating in CCM, which can be mathematically evidenced by the transfer function expressed in (35). It differs from the transfer function of the boost 3SSC-B-based converter presented in [31], which has characteristics like the classic boost converter.
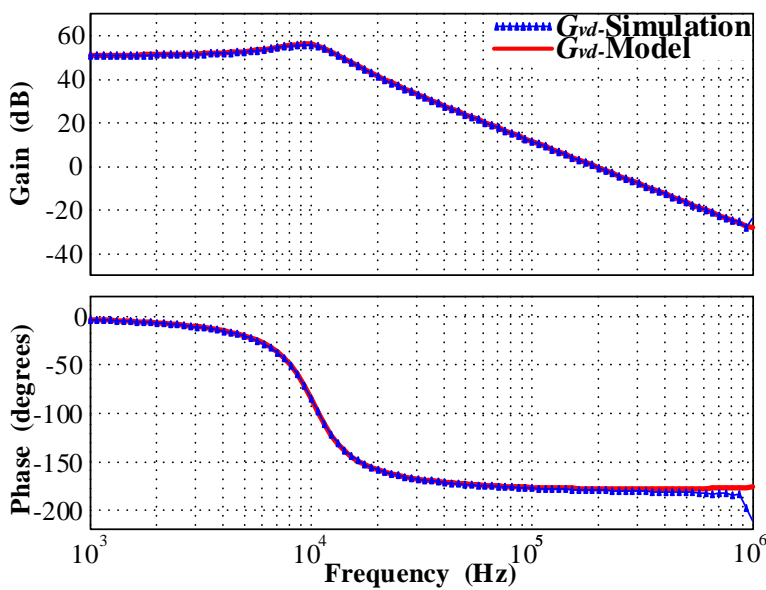

(a)

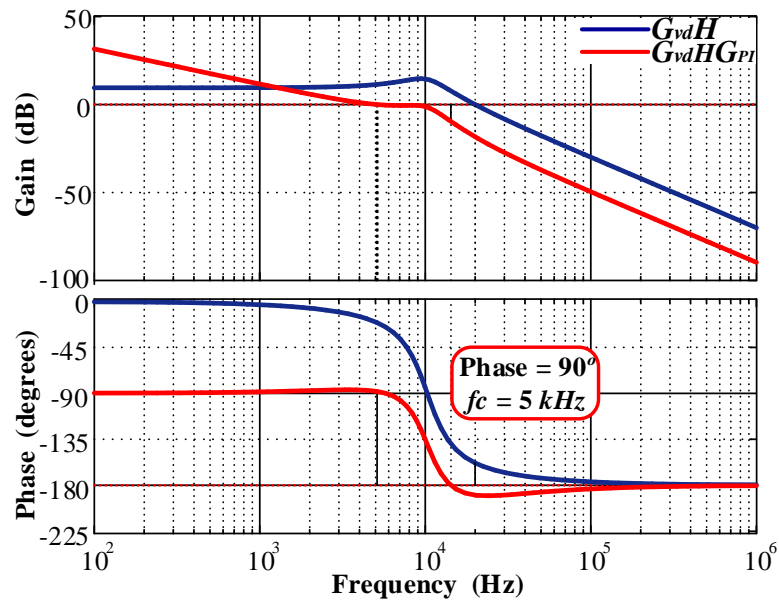

(b)

Figure 6. Bode diagram: (a) Validation of transfer function $G_{v d}(s)$; (b) open-loop transfer-function.

In this regard, by using the design specifications from Table 1 , the bode diagram of the transfer function $G_{v d}$, including the gain sensor $H=8.33 \times 10^{-3} \mathrm{~V} / \mathrm{V}$, is illustrated in Figure $6 \mathrm{~b}$ (blue curve). The average voltage-mode control technique is applied to the regulation of the output voltage of the converter and, due to the characteristic of the control-to-output transfer function, the PI controller was adopted. The conventional phase-margin and gain-margin stability criteria are applied, where a crossing frequency is around $1 / 4$ and $1 / 10$ of the switching frequency, and a phase margin $45^{\circ} \leq \mathrm{PM} \leq 90^{\circ}$ should be attended to provide a good response with an adequate output-voltage overshoot. As shown in Figure 6 (red in color), by using a proportional gain $K_{p}=0.1033$ and an integral gain $K_{i}=7944$ for the controller PI, the crossover frequency and phase margin obtained from the voltage control loop are $5 \mathrm{kHz}$ and $90^{\circ}$, respectively. 
Table 1. Design specifications.

\begin{tabular}{cc}
\hline Parameter & Value \\
\hline Input Voltage $\left(V_{i n}\right)$ & $180 \mathrm{~V}$ \\
Output Voltage $\left(V_{o}\right)$ & $300 \mathrm{~V}$ \\
Output Power $\left(P_{o}\right)$ & $600 \mathrm{~W}$ \\
Switching Frequency $\left(f_{s}\right)$ & $50 \mathrm{kHz}$ \\
Current Ripple $\left(\Delta I_{L}\right)$ & $0.15 I_{o}$ \\
Voltage Ripple $\left(\Delta V_{o}\right)$ & $0.01 V_{o}$ \\
Inductor $(L)$ & $L=1.3 \mathrm{mH}$, core NEE-42/21/15-IP12 by Thornton, $\mathrm{N}=53$ turns $-5 \times$ AWG26 \\
Capacitor $\left(C_{o}\right)$ & $C_{o}=180 \mathrm{nF} 1.1 \mathrm{kV}$, metal polyester film capacitor \\
Load $\left(R_{o}\right)$ & $150 \Omega$ \\
Autotransformer $(T)$ & $N_{p} / N_{S}=1 / 1$, core NEE-42/21/20-IP12 by Thornton, N $=29$ turns $-3 \times$ AWG26 \\
Switches $S_{1}-S_{2}$ & IGBT FGH20N60SFD, $I_{C}=20 \mathrm{~A}, V_{C E}=600 \mathrm{~V}$, by FAIRCHLD \\
Diodes $D_{1}-D_{2}$ & $V_{R}=600 \mathrm{~V}, I_{F}=14.5$ A, $V_{F}=1.5 \mathrm{~V}$, by CREE \\
\hline
\end{tabular}

\section{Comparison with Other Boost Converter Topologies}

Table 2 summarizes the main characteristics of the 3SSC-A-based boost converter compared to other structures with current source characteristics at the output and RHP zero free control-to-output transfer function. It is observed that the first-order KY converter has the lowest number of semiconductors, however, it has the same number of controlled switches as the 3SSC-A-based boost converter. On the other hand, since the controlled switches are in the same reference, the command scheme of the 3SSC-A-based boost could result in simpler circuits. The interleaved tri-state boost converter exhibits the largest number of semiconductors, requiring greater complexity in the command and control scheme among the aforementioned topologies. With regard to voltage stress, the first-order KY converter presents the least stress on the switches.

Table 2. Comparison among the 3SSC-A-based boost and other similar approaches in CCM.

\begin{tabular}{cccc}
\hline Parameter & {$[21]$} & {$[22]$} & 3SSC-A Boost \\
\hline Static gain & $1+D$ & $\frac{4+D}{2(1-D)}$ & $1+2 D$ \\
Voltage stress on the switches & $V_{\text {in }}$ & $V_{o}$ & $2 V_{\text {in }}$ \\
\# Switches & 2 & 4 & 2 \\
\# Diodes & 1 & 4 & 2 \\
Autotransformer & - & - & 1 \\
\# Capacitors & 2 & 1 & 1 \\
\# Inductors & 1 & 2 & 1 \\
Ripple frequency of $i_{L}$ & $f_{s}$ & $f_{s}$ & $2 f_{s}$ \\
Ripple frequency of $i_{C_{o}}$ & $f_{s}$ & $2 f_{s}$ & $2 f_{s}$ \\
Duty cycle range & $0<D<1$ & $0<D<1$ & $0<D<0.5$ \\
\hline
\end{tabular}

The 3SSC-A-based boost converter is the only one that uses an autotransformer, with a turn ratio equal to unity, which guarantees the distribution of current stress in the semiconductors. In addition, all the energy storage elements of this structure operate at twice the switching frequency, which provides a reduction in weight and volume compared to other topologies. In addition, the interleaved tri-state boost has a high voltage gain compared to other converters, however, its static gain has a nonlinear behavior and is dependent on the possible switching logic of this structure. It is important to remark that, although 3SSC-A-based boost operates with duty cycle less than 0.5 , the maximum static gain is equal to the 1st-order KY converter.

\section{Experimental Results}

The experimental set-up implemented to carry out the laboratory tests is shown in Figure 7. The power circuit of the 3SSC-A-based boost converter was assembled according to the parameters presented in Table 1 . It is noteworthy that, by applying the methodology presented in Section 2 for the autotransformer design, the NEE-30/15/14 core was found, however, due to the available components at the laboratory, the NEE- $42 / 21 / 20$ core was used. 
Figure 8 shows the control signals of the switches $S_{1}$ and $S_{2}$, demonstrating that the converter operates without overlapping of the pulses, with $\mathrm{D}=0.33$. Additionally, it is illustrated the maximum voltage of the $v_{S_{1}}$ is approximately $360 \mathrm{~V}$. The current $i_{S 1}$ increases linearly being approximately $2.2 \mathrm{~A}$. The waveforms related to the voltage and current stress on the switches $S_{1}$ and $S_{2}$ are shown in Figure 9. It is observed that the switches do not remain turned on simultaneously, with a 180-degree delay between the command signals being evident. It is worth remarking that the interaction between the autotransformer leakage inductance and the IGBT collector-emitter capacitance results in an equivalent resonant LC circuit in the activation process, which causes the current spikes seen in the currents $i_{S 1}$ and $i_{S 2}$ in Figure 9. Moreover, the leakage inductance would also cause voltage spikes on switches, however, these spikes were reduced by using RLD snubber circuits. Additionally, the effect of the autotransformer windings leakage inductance could be alleviated by increasing the coupling factor, which can be achieved by replacing the EE core with a toroidal core, increasing the occupation of the window area, and applying suitable interleaved winding techniques [32].

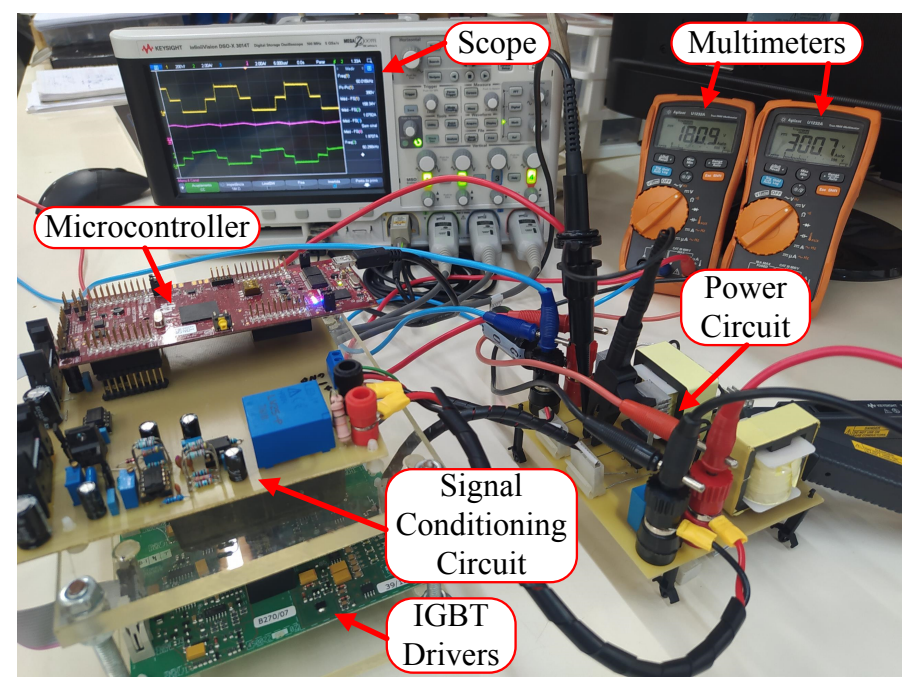

Figure 7. Experimental set-up.

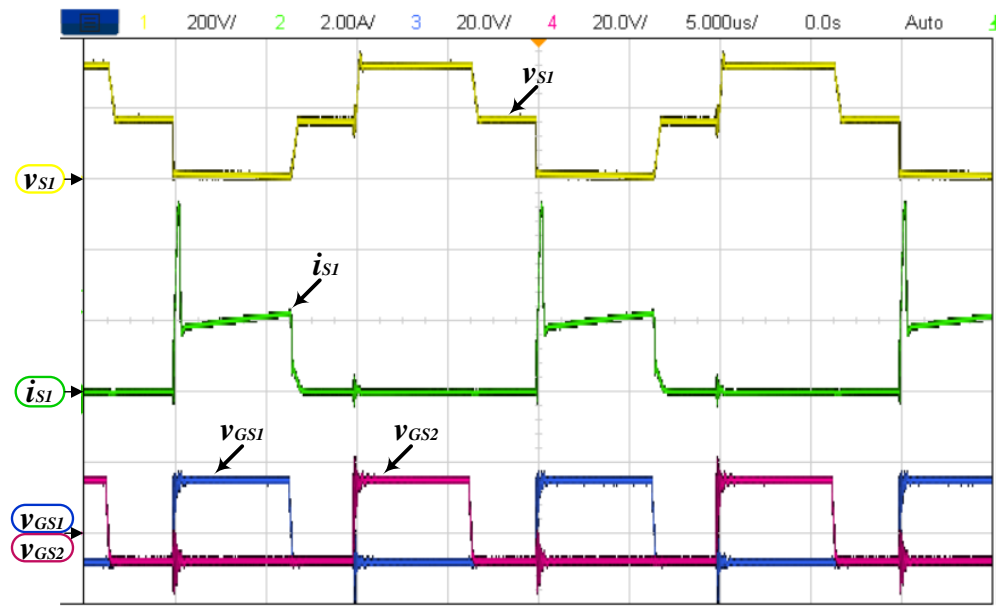

Figure 8. $v_{S_{1}}(200 \mathrm{~V} / \mathrm{div}) ; i_{S_{1}}(2 \mathrm{~A} / \mathrm{div}) ; V_{G S_{1}}(20 \mathrm{~V} / \mathrm{div}) ; V_{G S_{2}}(20 \mathrm{~V} / \mathrm{div}) ;$ time: $5 \mu \mathrm{s} / \mathrm{div}$. 


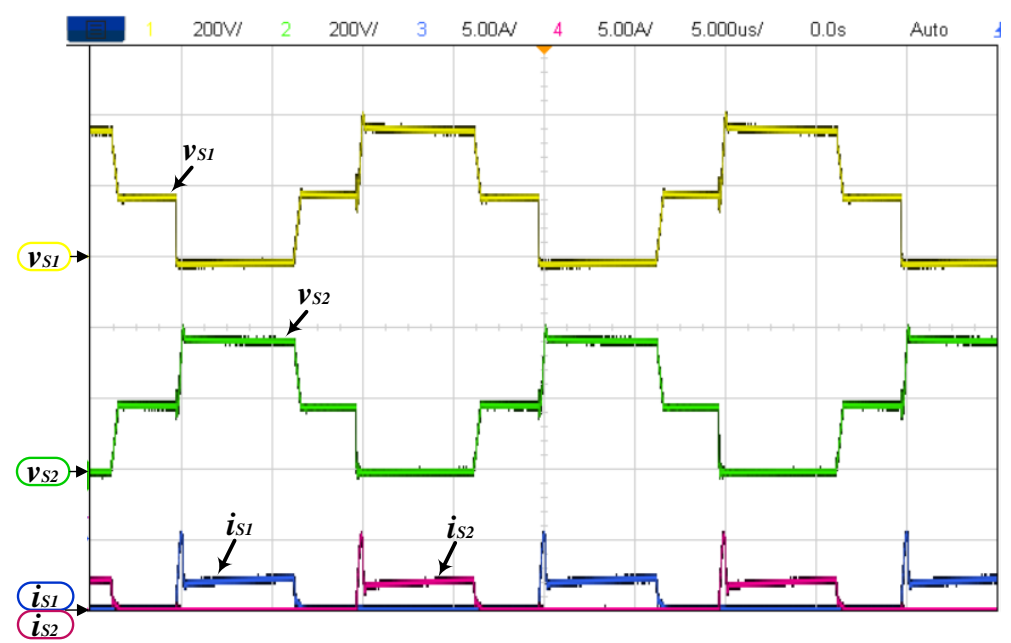

Figure 9. $v_{S_{1}}(200 \mathrm{~V} / \mathrm{div}) ; v_{S_{2}}(200 \mathrm{~V} / \mathrm{div}) ; i_{S_{1}}(5 \mathrm{~A} / \mathrm{div}) ; i_{S_{2}}(5 \mathrm{~A} / \mathrm{div}) ;$ time: $5 \mu \mathrm{s} / \mathrm{div}$.

In Figure 10, the voltage $v_{D_{1}}$, the current $i_{L}$, and the currents $i_{D_{1}}$ e $i_{S_{1}}$ are illustrated. The maximum reverse voltage on the diodes is equivalent to $2 V_{\text {in }} \approx-360 \mathrm{~V}$, according to the theoretical analysis. Looking at the currents $i_{S_{1}}$ and $i_{D_{1}}$, it can be verified that the switch $S_{1}$ and the diode $D_{1}$ do not operate simultaneously, validating the complement operation between these semiconductors. Furthermore, it can be observed, from the current $i_{L}$ 's behavior, that the converter operates in CCM, and the frequency of the ripple current $\Delta I_{L}$ is equal to $100 \mathrm{kHz}$, corresponding to twice the switching frequency, with an average value of $2 \mathrm{~A}$. Moreover, it can be seen the diodes $D_{1}$ and $D_{2}$ conduct simultaneously when the current $i_{L}$ decreases linearly, i.e., the moment when the switches $S_{1}$ and $S_{2}$ are turned off, and the current through each diode is equivalent to half of the current $i_{L}$, with an average value of $1 \mathrm{~A}$.

Figure 11 shows the waveforms of the voltage $V_{i n}$, the voltage $V_{o}$, the current $i_{L}$, and the input current $i_{i n}$. These results evidence that the converter operates as step-up structure, with $V_{o}$ equal to $300 \mathrm{~V}$, corresponding to the gain required. It is verified that the current $i_{\text {in }}$ presents a greater ripple than the current $i_{L}$ and its shape shows the characteristic of the voltage-fed converter, in contrast to the classic boost converter and the 3SSC-B-based boost topology, which present current-fed converter characteristic.

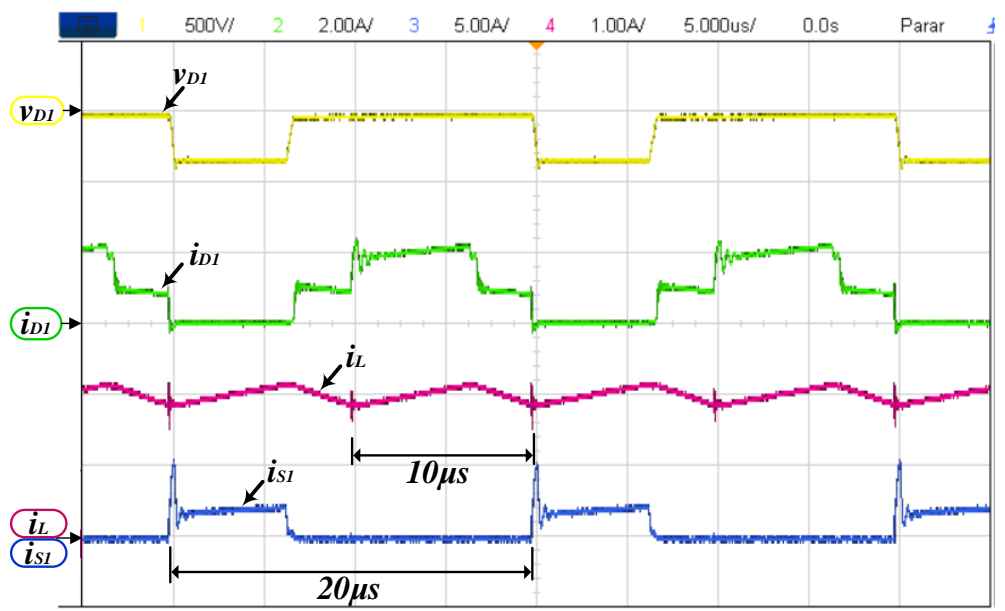

Figure 10. $v_{D_{1}}(500 \mathrm{~V} / \mathrm{div}) ; i_{D_{1}}(2 \mathrm{~A} / \mathrm{div}) ; i_{L}(1 \mathrm{~A} / \mathrm{div}) ; i_{S_{1}}(5 \mathrm{~A} / \mathrm{div}) ;$ time: $5 \mu \mathrm{s} / \mathrm{div}$. 


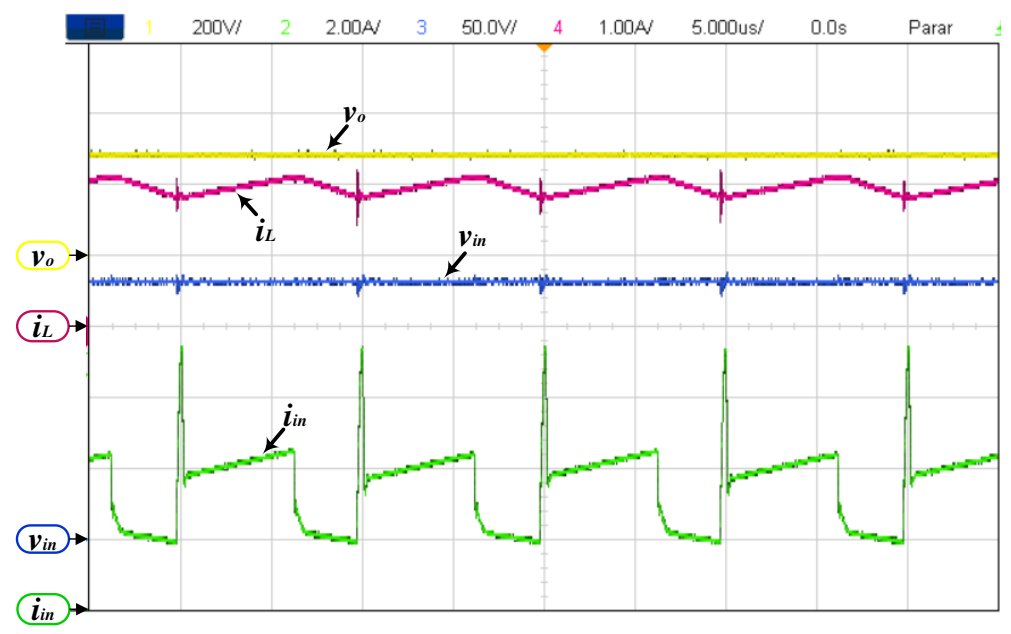

Figure 11. $v_{o}(200 \mathrm{~V} / \mathrm{div}) ; i_{L}(1 \mathrm{~A} / \mathrm{div}) ; v_{\text {in }}(50 \mathrm{~V} / \mathrm{div}) ; i_{\text {in }}(2 \mathrm{~A} / \mathrm{div}) ;$ time: $5 \mu \mathrm{s} / \mathrm{div}$.

The dynamic responses of $V_{o}, i_{L}$, and $i_{D_{1}}$, during a load variation, are shown in Figure 12. Initially, at $t=400 \mathrm{~ms}$ the load decrease from $600 \mathrm{~W}$ to $300 \mathrm{~W}$, and then, at $t=1250 \mathrm{~ms}$, the load is increased from $300 \mathrm{~W}$ to $600 \mathrm{~W}$. It can be verified an output-voltage overshoot lower than $6 \%$ of the rated voltage.

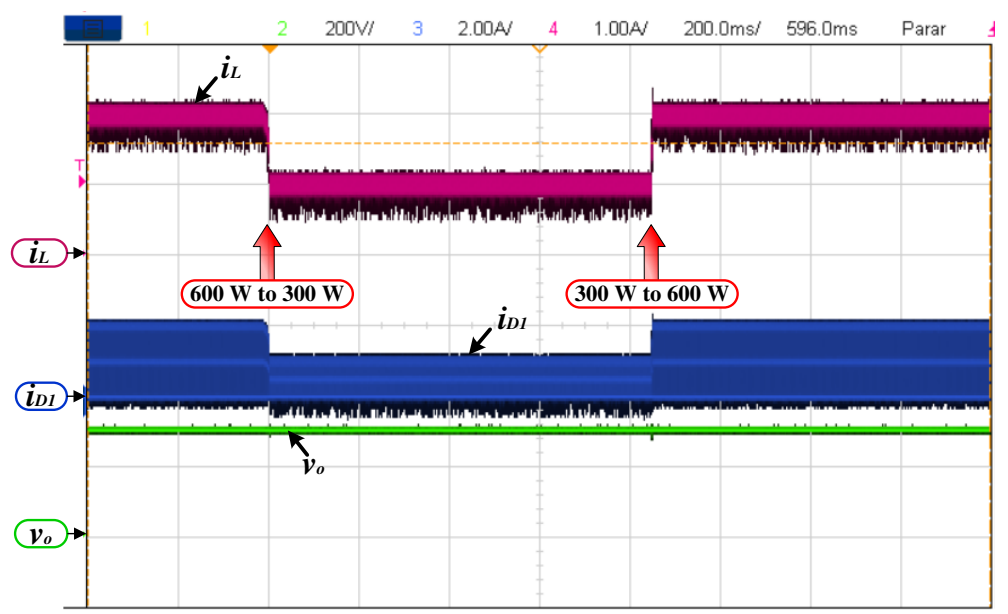

Figure 12. $v_{o}(200 \mathrm{~V} / \mathrm{div}) ; i_{D_{1}}(2 \mathrm{~A} / \mathrm{div}) ; i_{L}(1 \mathrm{~A} / \mathrm{div}) ;$ time: $200 \mathrm{~ms} / \mathrm{div}$.

According to the loss model described in Section 2.2 and Table 2, the distribution of theoretical power losses in the converter, operating at full load, is shown in Figure 13, which is equivalent to the total theoretical power losses of $17.2 \mathrm{~W}$ and theoretical efficiency of around $97.2 \%$. It is observed that semiconductors are the elements that most contribute to total losses, and the power losses in magnetic elements are mainly given by the cooper losses. Moreover, due to the low current ripple and the small ESR, it can be noted that the power losses in the capacitor are extremely reduced when compared to the other elements. The efficiency of the experimental prototype was evaluated in a load range of $100 \mathrm{~W}$ to $600 \mathrm{~W}$, as shown in Figure 14. It is verified that the performance of the prototype is greater than $91 \%$ in the whole range of defined power, at nominal load this is approximately $96.8 \%$. 


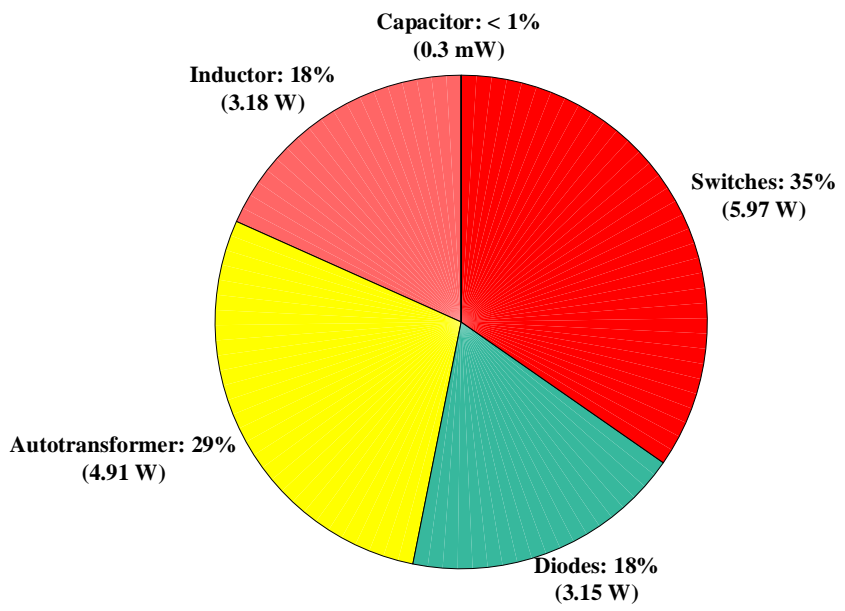

Figure 13. Theoretical distribution of power losses.

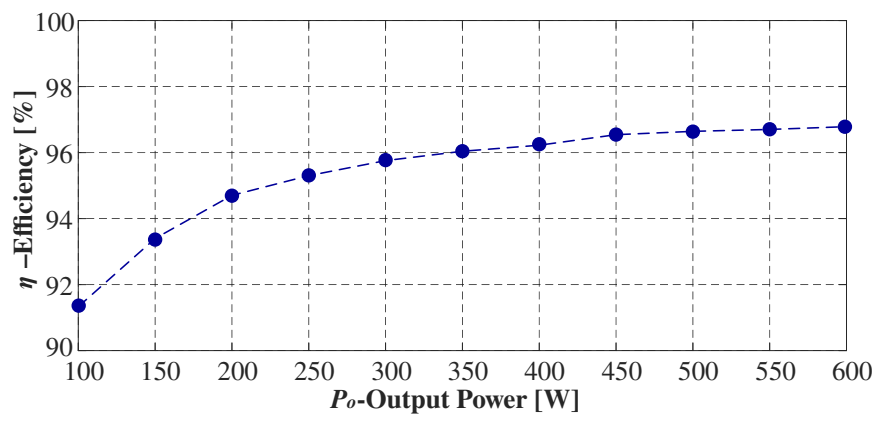

Figure 14. Experimental efficiency curve.

In nominal power conditions, the thermal distribution in the converter is evaluated by means of a thermal imaging camera, as presented in Figure 15. Due to the current division between these components, the distribution of thermal losses between the semiconductors, which is related to the operating characteristic of the 3SSC-A. At full load, the maximum component temperature is less than $45^{\circ} \mathrm{C}$.

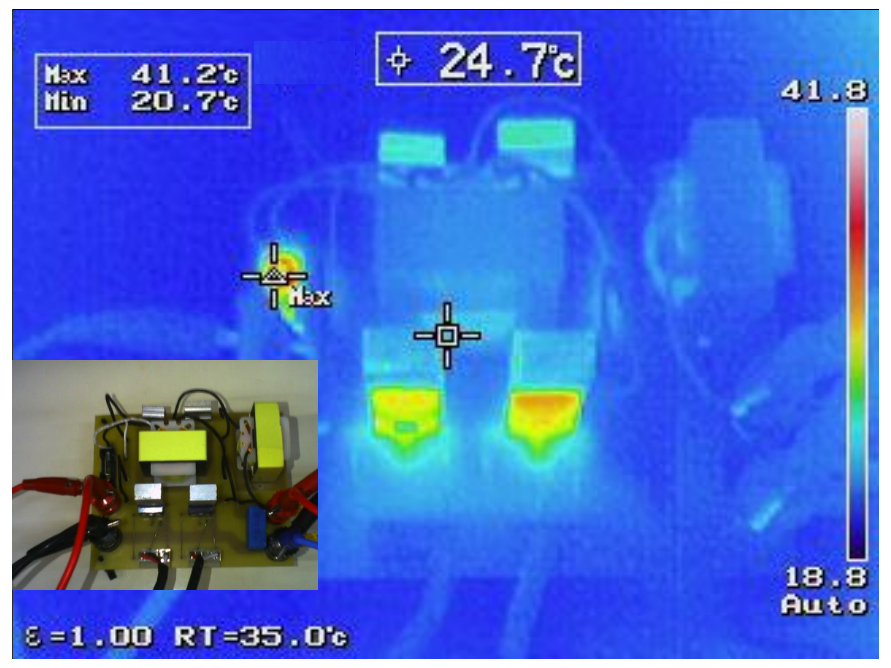

Figure 15. Infrared image of the converter at full load.

\section{Conclusions}

This paper presented the 3SSC-A-based boost converter, filling a gap in the literature, regarding the complete study of this topology. The incorporation of the type-A 3SSC structure results in advantageous characteristics compared to the classic boost converters, 
offering a low-ripple in the current of the output capacitor, which reduces the losses due to the capacitor's series resistance and, consequently, increases the useful life of this element.

Through the study of the converter dynamics, it was found that, unlike classic boost topologies, the control-to-output transfer function of the 3SSC-A-based boost has a minimum-phase characteristic, which allows the use of only one control-loop, with a simple controller, offering fast load transient responses, similar to the classic buck converter behavior. Besides, the high-level efficiency, the 3SSC-A-based boost converter presents the typical advantages related to 3SSC, such as weight and volume reduction of passive components, division of the current stress between semiconductors and losses thermal distribution, providing reducing the size of the heat sinks.

The 3SSC-A-based boost converter becomes an attractive solution for step-up structures that require to supply of critical loads sensitive with low current ripple. Furthermore, the use of the structure in several energy conditioning applications that require high performance and high power density could be explored.

Author Contributions: Conceptualization, L.C.S. and F.J.M.d.S.; formal analysis, L.C.S., L.D.O.A. and L.d.S.d.C.e.S.; funding acquisition, F.J.M.d.S.; methodology, L.C.S. and L.D.O.A.; resources, F.J.M.d.S.; software, L.C.S. and L.D.O.A.; validation, L.C.S. and L.D.O.A.; visualization, D.C.M.; writing—original draft, L.C.S.; writing—review and editing, L.d.S.d.C.e.S., L.D.O.A. and F.J.M.d.S All authors have read and agreed to the submitted version of the manuscript.

Funding: This research was supported in part by the Coordenação de Aperfeiçoamento de Pessoal de Nível Superior, Brazil (CAPES), Finance Code 001 and the São Paulo Research Foundation (FAPESP), Grant No. 2019/180204.

Institutional Review Board Statement: Not applicable.

Informed Consent Statement: Not applicable.

Data Availability Statement: Not applicable.

Acknowledgments: This work was supported by the Goias Federal Institute of Education, Science, and Technology_Jataí and the Power Electronics Laboratory-UNESP/FEIS.

Conflicts of Interest: The authors declare no conflict of interest.

\section{References}

1. Zogogianni, C.G.; Tatakis, E.C.; Porobic, V. Investigation of a Non-isolated Reduced Redundant Power Processing DC/DC Converter for High-Power High Step-Up Applications. IEEE Trans. Power Electron. 2019, 34, 5229-5242. [CrossRef]

2. Varesi, K.; Hosseini, S.H.; Sabahi, M.; Babaei, E. Modular non-isolated multi-input high step-up dc-dc converter with reduced normalised voltage stress and component count. IET Power Electron. 2018, 11, 1092-1100. [CrossRef]

3. Yari, K.; Shahalami, S.H.; Mojallali, H. High step-up isolated dc-dc converter with single input and double output and soft-switching performance for renewable energy applications. IET Power Electron. 2019, 12, 2942-2952. [CrossRef]

4. Biela, J.; Badstuebner, U.; Kolar, J.W. Impact of Power Density Maximization on Efficiency of DC-DC Converter Systems. IEEE Trans. Power Electron. 2009, 24, 288-300. [CrossRef]

5. Outeiro, M.T.; Buja, G.; Czarkowski, D. Resonant Power Converters: An Overview with Multiple Elements in the Resonant Tank Network. IEEE Ind. Electron. Mag. 2016, 10, 21-45. [CrossRef]

6. Kelly, A. Current Share in Multiphase DC-DC Converters Using Digital Filtering Techniques. IEEE Trans. Power Electron. 2009, 24, 212-220. [CrossRef]

7. Bascope, G.V.T.; Barbi, I. Generation of a family of non-isolated DC-DC PWM converters using new three-state switching cells. In Proceedings of the 2000 IEEE 31st Annual Power Electronics Specialists Conference. Conference Proceedings (Cat. No.00CH37018), Galway, Ireland, 23 June 2000; Volume 2, pp. 858-863. [CrossRef]

8. Torrico-bascope, G.V.; Vasconcelos, S.A.; Torrico-bascope, R.P.; M. Antunes, F.L.; De Oliveira, D.S.; C. Branco, C.G. A High Step-Up DC-DC Converter Based on Three-State Switching Cell. In Proceedings of the 2006 IEEE International Symposium on Industrial Electronics, Montreal, QC, Canada, 9-13 July 2006; Volume 2, pp. 998-1003. [CrossRef]

9. Torrico-Bascope, G.V.; Barbi, I. A single phase PFC $3 \mathrm{~kW}$ converter using a three-state switching cell. In Proceedings of the 2004 IEEE 35th Annual Power Electronics Specialists Conference (IEEE Cat. No.04CH37551), Aachen, Germany, 20-25 June 2004; Volume 5, pp. 4037-4042. [CrossRef]

10. Peraça, M.T.; Batista, F.A.B.; Marcelino, L.M. Inversor de cinco níveis baseado na célula de comutação de três estados. In Proceedings of the 2010 9th IEEE/IAS International Conference on Industry Applications-INDUSCON 2010, Sao Paulo, Brazil, 8-10 November 2010; pp. 1-6. [CrossRef] 
11. Araujo, S.V.; Torrico-Bascope, R.P.; Torrico-Bascope, G.V. Highly Efficient High Step-Up Converter for Fuel-Cell Power Processing Based on Three-State Commutation Cell. IEEE Trans. Ind. Electron. 2010, 57, 1987-1997. [CrossRef]

12. Balestero, J.P.R.; Tofoli, F.L.; Fernandes, R.C.; Torrico-Bascope, G.V.; Mendes de Seixas, F.J. Power Factor Correction Boost Converter Based on the Three-State Switching Cell. IEEE Trans. Ind. Electron. 2012, 59, 1565-1577. [CrossRef]

13. Balestero, J.P.R.; Tofoli, F.L.; Torrico-Bascopé, G.V.; de Seixas, F.J.M. A DC-DC Converter Based on the Three-State Switching Cell for High Current and Voltage Step-Down Applications. IEEE Trans. Power Electron. 2013, 28, 398-407. [CrossRef]

14. Larico, H.R.E.; de Tomin, V.P.; Larico, E.R.E. Unified Second-Stage LC Filter Applied in the Three-State Switching Cell Buck-Boost Converter: Static and Dynamic Analysis and Experimentation. IEEE Trans. Ind. Electron. 2020, 67, 225-234. [CrossRef]

15. Tofoli, F.L.; De Andrade Tavares, D.; De Assis Saldanha, J.I. Survey on topologies based on the three-state and multi-state switching cells. IET Power Electron. 2019, 12, 967-982. [CrossRef]

16. Torrico-Bascope, R.P.; Tofoli, F.L.; Castelo Branco, C.G.; Tavares Cruz, C.M. Three-state switching cell (3SSC)-based non-isolated dc-dc boost-type converter with balanced output voltage and wide voltage conversion range. IET Power Electron. 2018, 11, 1217-1223. [CrossRef]

17. Alcazar, Y.J.A.; de Souza Oliveira, D.; Tofoli, F.L.; Torrico-Bascopé, R.P. DC-DC Nonisolated Boost Converter Based on the Three-State Switching Cell and Voltage Multiplier Cells. IEEE Trans. Ind. Electron. 2013, 60, 4438-4449. [CrossRef]

18. Silveira, G.C.; Tofoli, F.L.; Bezerra, L.D.S.; Torrico-Bascopé, R.P. A Nonisolated DC-DC Boost Converter With High Voltage Gain and Balanced Output Voltage. IEEE Trans. Ind. Electron. 2014, 61, 6739-6746. [CrossRef]

19. Barreto, L.H.S.C.; Praça, P.P.; Oliveira, D.S.; Silva, R.N.A.L. High-Voltage Gain Boost Converter Based on Three-State Commutation Cell for Battery Charging Using PV Panels in a Single Conversion Stage. IEEE Trans. Power Electron. 2014, 29, 150-158. [CrossRef]

20. Forouzesh, M.; Siwakoti, Y.P.; Gorji, S.A.; Blaabjerg, F.; Lehman, B. Step-Up DC-DC Converters: A Comprehensive Review of Voltage-Boosting Techniques, Topologies, and Applications. IEEE Trans. Power Electron. 2017, 32, 9143-9178. [CrossRef]

21. Hwu, K.I.; Yau, Y.T. KY Converter and Its Derivatives. IEEE Trans. Power Electron. 2009, 24, 128-137. [CrossRef]

22. Rana, N.; Kumar, M.; Ghosh, A.; Banerjee, S. A Novel Interleaved Tri-State Boost Converter With Lower Ripple and Improved Dynamic Response. IEEE Trans. Ind. Electron. 2018, 65, 5456-5465. [CrossRef]

23. Kapat, S.; Patra, A.; Banerjee, S. A Current-Controlled Tristate Boost Converter With Improved Performance Through RHP Zero Elimination. IEEE Trans. Power Electron. 2009, 24, 776-786. [CrossRef]

24. Souza, L.C.; de Seixas, F.J.M.; de Oro Arenas, L.; Carvalho Morais, D.; d. Souza da Costa e Silva, L. A Non-Isolated DC-DC Boost Converter with Three-State Switching Cell. In Proceedings of the 2019 IEEE 15th Brazilian Power Electronics Conference and 5th IEEE Southern Power Electronics Conference (COBEP/SPEC), Santos, Brazil, 1-4 December 2019; pp. 1-6. [CrossRef]

25. Lim, H.; Hwang, J.; Kwon, S.; Baek, H.; Uhm, J.; Lee, G. A Study on Real Time IGBT Junction Temperature Estimation Using the NTC and Calculation of Power Losses in the Automotive Inverter System. Sensors 2021, 21, 2454. [CrossRef]

26. Hadi, A.A.; Fu, X.; Challoo, R. IGBT module loss calculation and thermal resistance estimation for a grid-connected multilevel converter. In Wide Bandgap Power and Energy Devices and Applications III; Matin, M., Chowdhury, S., Dutta, A.K., Eds.; International Society for Optics and Photonics, SPIE: San Diego, CA, USA, 2018; Volume 10754, pp. 19-29.

27. Barrios, E.L.; Ursúa, A.; Marroyo, L.; Sanchis, P. Analytical Design Methodology for Litz-Wired High-Frequency Power Transformers. IEEE Trans. Ind. Electron. 2015, 62, 2103-2113. [CrossRef]

28. Pan, X.; Li, H.; Liu, Y.; Zhao, T.; Ju, C.; Rathore, A.K. An Overview and Comprehensive Comparative Evaluation of Current-FedIsolated-Bidirectional DC/DC Converter. IEEE Trans. Power Electron. 2020, 35, 2737-2763. [CrossRef]

29. ELGSTROM, T.; NORDGREN, L. Evaluation and Design of High Frequency Transformers for On Board Charging Applications. Ph.D. Thesis, Chalmers University Of Technology, Gothenburg, Sweden, 2016.

30. Erickson, R.; Maksimovic, D. Fundamentals of Power Electronics; Power electronics; Springer: New York, NY, USA, 2001.

31. Cesar, E.L.; Bascopé, R.P.T.; Lafuente, C.O. Modelagem de um Conversor Boost de três Estados; Congresso Brasileiro de Automática: Bonito, Brazil, 2010; pp. 3073-3080.

32. Stadler, A.; Albach, M. The influence of the winding layout on the core losses and the leakage inductance in high frequency transformers. IEEE Trans. Magn. 2006, 42, 735-738. [CrossRef] 